\title{
Sweet blood with bitter consequences : Sexual dysfunction in diabetic women
}

\author{
Original \\ Article \\ Ihab Younis, Osama H. AlKady, Rasha M. Emam \\ Department of Dermatology and Andrology, Faculty of Medicine, Benha University, Benha, \\ Egypt
}

\begin{abstract}
Background: Prevalence of diabetes mellitus (DM) is on the rise. Its effect on different body systems is well known. Sexual dysfunctions (SD) in men and women may be related to DM. However, SD is more difficult to diagnose and treat in women than in men because of the intricacy of the female sexual response. Also, the literature is limited addressing female sexual dysfunction in DM, and this aspect of female health, is often ignored in clinical practice in women with DM.

Objective: : To determine the frequency and types of SD and its causative factors among the diabetic women.

Patients and methods: This cross sectional study used a self-report questionnaire taken from the FSFI with addition of questions suiting the purpose of the study. Participants of this study were 407 married women with regular sexual activity who attended the outpatient clinics at the National Institute of Diabetes Mellitus in Cairo during the period from September to December 2018.

Results: The commonest age group of women was 40-49 years, most of them were obese and most of them can only read and write. Most participants (42\%) suffered from diabetes for more than 10 years and $70.7 \%$ were of type II diabetes. Diabetic complications included peripheral neuropathy, hypertension and coronary artery disease. At least one SD was present in $66.3 \%$ of participants including dyspareunia followed by sexual dissatisfaction followed by low libido. Duration and control of diabetes, BMI, age and diabetic complications were determining factors for the occurrence of SD.

Conclusion: SD are common in diabetic women. The most commonly encountered SD are dyspareunia, sexual dissatisfaction and low libido.
\end{abstract}

Key Words: Diabetes, dysfunction, sexual, women

Received: 05 November 2019, Accepted: 22 November 2019

Corresponding Author: Osama H. AlKady, Department of Dermatology and Andrology, Faculty of Medicine, Benha University, Benha, Egypt, Tel.: 0242144645, E-mail: oselfady452003@yahoo.com

ISSN: 2090-6048, June 2019 Vol.9, No.2

\section{INTRODUCTION}

Rates of diabetesmellitus are growing worldwide. In 2013, 382 million adults were identified with diabetes worldwide. This number may raise to 592 million in $2030^{[1]}$. A 2017 report from Centers for Disease Control and Prevention (CDC), estimated that in the United States, as of $2015,30.3$ million persons of all ages, or $9.4 \%$ of the population, had diabetes ${ }^{[2]}$.

In Egypt, the average prevalence of diabetes mellitus is round $15.56 \%$ among adults between twenty and seventy nine years of age. It is alarming that diabetes occurrence in Egypt has accelerated hastily within an extraordinarily brief period from about 4.4 million in 2007 to 7.5 million in 2013. It is predicted this number will bounce up to 13.1 million with the end of $2030^{[2]}$. This high prevalence continues to amplify as a result of elevated prevalence of central type of obesity, change in feeding habits, sedentary lifestyle, accelerated incidence of hepatitis $\mathrm{C}$ virus infection, and may be the elevated use of uncontrolled pesticides $^{[3]}$.

There is disagreement about the existence of sexual dysfunction in females having diabetes, with the documented occurrence ranges between $25 \%$ and $71 \%{ }^{[4]}$. It is feasible that this wide variation in prevalence displays the distinctive populations evaluated and the different inclusion criteria used, such as the age regarded (childbearing age or postmenopausal), body mass index (BMI), endocrine system disorders, and different drugs usedby studied females ${ }^{[5]}$.

A Turkish study ${ }^{[6]}$ on 200 diabetic females discovered that the most affected sexual domains were generally arousal disorder which rate for $(20.5 \%)$, orgasm $(19.5 \%)$, lubrication (18.8\%) and satisfaction disorder (17.5\%). According to the findings of this Turkish study, SD used to be seen greater amongst women who had Type 1 diabetes, had diabetes for more than 10 years, developed 
diabetic complications and did not use her medications as prescribed. Also, it was noticed thatfemalesdiagnosed with depression suffered from sexual dysfunction more than other women.

The present study was conducted to evaluate the frequency of SD and the effects of diabetes mellitus on female sexuality in a sample of Egyptian diabetic women.

\section{PATIENTS AND METHODS}

This is a cross sectional study that started out after taking the approval of both, Benha Ethical Committee and Dermatology and Andrology Department, Faculty of medicine in Benha University.

The study constructed depending on data collected from a self-report questionnaire which was designed in accordance to Female Sexual Function Index (FSFI) ${ }^{[7]}$ and the validated Arabic translation ${ }^{[8]}$. Some questions were added to the questionnaire like, age of onset, duration, level of control and drugs used to control diabetes. The goals, the method and the details of the questionnaire have been explained and defined to the ladies before taking their informed consent. Privacy and confidentiality had been assured.Participants of this study had been 407 diabetic females recruited from those attending the Diabetes and Endocrinology outpatient clinics at the National Institute of Diabetes Mellitus. All have been married females with ordinary sexual relation. Divorced, severely ill, widowed pregnant or lactating females had been excluded from the study.

\section{Statistical analysis}

FSFI total score of $\leq 26.55$ used to be viewed diagnostic of Female Sexual Dysfunction (FSD). Desire rating of $\leq 2.4$ was regarded diagnostic of desire dysfunction, arousal rating of $\leq 4.5$ was once regarded diagnostic of arousal dysfunction, lubrication rating of $\leq 3.3$ was once considered diagnostic of lubrication dysfunction, orgasm score of $\leq 4.8$ was considered diagnostic of orgasm dysfunction, satisfaction score of $\leq 5.2$ was regarded diagnostic of satisfaction dysfunction, pain rating of $\leq 2$ was once viewed diagnostic of dyspareunia.

Data have been analyzed the use of IBM SPSS software bundle model 20.0. (Armonk, NY: IBM Corp). Qualitative information have been described using number and percent. Significance of the results was judged at the level of $p>0.05$.

\section{RESULTS}

\section{Demographic data}

The age range of women participating in this study was 20 to 54 . The most common age group was $40-49$ years
(48.6\%). Most of them (69\%) were obese (BMI of 25 or more), and most of them either finished their secondary school $(12.2 \%)$, or can only read and write $(85.7 \%)$.

\section{Diabetes data}

Table 1 indicates that most participants $(42 \%)$ suffered from diabetes for more than 10 years and that $70.7 \%$ of the cases were of type II diabetes. Insulin was the treatment received by $51.5 \%$ of cases, however, only $30 \%$ had controlled diabetes. Regarding complications, $89.4 \%$ of participants were suffering from peripheral neuropathy, $27.5 \%$ were suffering from hypertension and $3.9 \%$ had coronary artery disease. Among hypertensive patients 58\% received ACE inhibitors and $41.9 \%$ were treated with beta blockers.

\section{Sexual dysfunctions in participants}

More than two thirds of participants (66.3\%) suffered from at least one sexual dysfunction (SD). The commonest SD was pain during intromission $(71.3 \%)$ followed by sexual dissatisfaction (59.7\%) followed by low libido (58.2\%) (Table 2).

\section{Determinants of sexual dysfunction in diabetic women}

1. Duration of diabetes: SD was found to increase significantly with increase in duration of diabetes. The most common SD in this respect was dyspareunia $(95 \%$ with duration $<10$ years) (Table 3 ).

2. Control of diabetes: Uncontrolled subjects significantly suffered more from SD than controlled ones. Pain domain was the most significantly affected (78.2\%) (Table 4).

3. Body mass index: Obese women significantly suffered from SD more than non-obese women. Dissatisfaction was the most common SD (74.7\%) in obese women (Table 5).

4. Age: incidence of SD significantly increased with advance in age. All women in age group 50+ suffered from low sexual desire (Table 6).

5. Diabetic complications: patients suffering from hypertension, coronary artery disease and peripheral neuropathy had significantly more SD than patients not suffering from diabetic complications. Hypertensive women significantly suffered from low desire (89.2\%) while all women with coronary artery disease significantly suffered from low desire and dyspareunia. Dyspareunia was the commonest SD (73.6\%) in patients with peripheral neuropathy (Table 7).

NB: Type I and Type II diabetic patients showed no difference in incidence of SD. 
Table 1: Data of diabetes mellitus

All cases

$(\mathrm{n}=407)$

$\mathrm{n}$

$\%$

Type of diabetes

Type I

119

Type II

Duration of diabetes (years)

$<1$ year

$1-5$ years

$62-15.2$

$6-10$ years

27

$>10$ years

Diabetes medication

Oral hypoglycemic drugs

Insulin

Diabetes control

Uncontrolled

Controlled

Diabetes complications

Hypertension

$122 \quad 30.0$

Coronary artery disease

$112 \quad 27.5$

Peripheral neuropathy

Hypertension treatment

ACE inhibitors

Capoten

Sinopril

Beta blockers

Concor5

41.9

Atenol

Table 2: Dysfunction of different sexual domains.

\begin{tabular}{lcc}
\hline Dysfunction & $\mathrm{n}$ & $\%$ \\
\hline Total FSD & 270 & 66.3 \\
Low desire & 237 & 58.2 \\
& & 56 \\
Arousal disorder & 228 & 53.3 \\
Lubrication disorder & 217 & 56 \\
Orgasm disorder & 228 & 59.7 \\
Satisfaction disorder & 243 & 71.3 \\
Pain disorder & 290 & \\
\hline
\end{tabular}


Table 3: Sexual dysfunction in relation to duration of diabetes (years).

\begin{tabular}{|c|c|c|c|c|c|c|c|c|c|c|}
\hline & \multicolumn{8}{|c|}{ Duration of diabetes (years) } & \multirow{3}{*}{ Test of sig. } & \multirow{3}{*}{$P$} \\
\hline & \multicolumn{2}{|c|}{$\begin{array}{c}<1 \\
(n=64)\end{array}$} & \multicolumn{2}{|c|}{$\begin{array}{c}1-5 \\
(n=62)\end{array}$} & \multicolumn{2}{|c|}{$\begin{array}{c}6-10 \\
(n=110)\end{array}$} & \multicolumn{2}{|c|}{$\begin{array}{c}>10 \\
(\mathrm{n}=171)\end{array}$} & & \\
\hline & $\mathrm{n}$ & $\%$ & $\mathrm{n}$ & $\%$ & $\mathrm{n}$ & $\%$ & $\mathrm{n}$ & $\%$ & & \\
\hline Total FSD & 6 & 9 & 15 & 24 & 90 & 81.8 & 159 & 92.9 & $\chi^{2}=40.533^{*}$ & $p<0.001^{*}$ \\
\hline Low desire & 7 & 10.9 & 19 & 30 & 60 & 54 & 151 & 88 & $\chi^{2}=38.977^{*}$ & $p<0.001^{*}$ \\
\hline Arousal disorder & 6 & 9 & 14 & 22.5 & 58 & 52.7 & 150 & 87.7 & $\chi^{2}=25.553^{*}$ & $p<0.001^{*}$ \\
\hline Lubrication disorder & 8 & 12.5 & 10 & 16 & 64 & 58 & 135 & 78.9 & $\chi^{2}=34.5 .5^{*}$ & $p<0.001^{*}$ \\
\hline Orgasm disorder & 10 & 15.6 & 10 & 16 & 58 & 52.7 & 150 & 87.7 & $\chi^{2}=25.011^{*}$ & $p<0.001^{*}$ \\
\hline Satisfaction disorder & 8 & 12.5 & 26 & 41.9 & 64 & 58 & 145 & 84.7 & $\chi^{2}=25.635^{*}$ & $p<0.001^{*}$ \\
\hline Pain disorder & 4 & 6 & 30 & 48.3 & 97 & 88.8 & 159 & 95 & $\chi^{2}=50.469 *$ & $p<0.001^{*}$ \\
\hline
\end{tabular}

Table 4: Sexual dysfunction in relation to disease control.

\begin{tabular}{|c|c|c|c|c|c|c|}
\hline & \multicolumn{2}{|c|}{$\begin{array}{l}\text { Uncontrolled } \\
(\mathrm{n}=285)\end{array}$} & \multicolumn{2}{|c|}{$\begin{array}{c}\text { Controlled } \\
(\mathrm{n}=122)\end{array}$} & \multirow[t]{2}{*}{ Test of sig. } & \multirow[t]{2}{*}{$P$} \\
\hline & $\mathrm{n}$ & $\%$ & $\mathrm{n}$ & $\%$ & & \\
\hline Total FSD & 199 & 69.8 & 71 & 58 & $\chi^{2}=0.224^{*}$ & $<0.001 *$ \\
\hline Low desire & 162 & 56.8 & 75 & 61.5 & $\chi^{2}=0.754$ & 0.385 \\
\hline Arousal disorder & 150 & 58 & 67 & 54.9 & $\chi^{2}=0.465$ & 0.495 \\
\hline Lubrication disorder & 153 & 53.7 & 64 & 52.5 & $\chi^{2}=0.052$ & 0.820 \\
\hline Orgasm disorder & 153 & 53.7 & 64 & 52.5 & $\chi^{2}=0.052$ & 0.820 \\
\hline Satisfaction disorder & 172 & 60.4 & 71 & 58.2 & $\chi^{2}=0.165$ & 0.685 \\
\hline Pain disorder & 223 & 78.2 & 67 & 54.9 & $\chi^{2}=22.696^{*}$ & $<0.001^{*}$ \\
\hline
\end{tabular}


Table 5: Sexual dysfunction relation to body mass index (BMI).

All cases $(n=407)$

\begin{tabular}{|c|c|c|c|}
\hline \multicolumn{2}{|c|}{$\begin{array}{c}\text { Obese } \\
(n=281)\end{array}$} & \multicolumn{2}{|c|}{$\begin{array}{c}\text { Non obese } \\
(n=126)\end{array}$} \\
\hline $\mathrm{n}$ & $\%$ & $\mathrm{n}$ & $\%$ \\
\hline 190 & 71 & 80 & 63 \\
\hline \multicolumn{4}{|c|}{$54.773^{*}\left(<0.001^{*}\right)$} \\
\hline 195 & 69 & 42 & 33 \\
\hline \multicolumn{4}{|c|}{$49.991^{*}(<0.001)$} \\
\hline 190 & 67.6 & 38 & 30 \\
\hline \multicolumn{4}{|c|}{$40.686^{*}\left(<0.001^{*}\right)$} \\
\hline 200 & 71 & 17 & 13 \\
\hline \multicolumn{4}{|c|}{$54.773^{*}\left(<0.001^{*}\right)$} \\
\hline 196 & 69.7 & 32 & 25 \\
\hline \multicolumn{4}{|c|}{$64.681^{*}\left(<0.001^{*}\right)$} \\
\hline 210 & 74.7 & 33 & 26 \\
\hline \multicolumn{4}{|c|}{$36.418^{*}\left(<0.001^{*}\right)$} \\
\hline 210 & 74 & 80 & 63 \\
\hline \multicolumn{4}{|c|}{$26.635^{*}\left(<0.001^{*}\right)$} \\
\hline
\end{tabular}


Table 6: Sexual dysfunction in relation to age.

\begin{tabular}{|c|c|c|c|c|c|c|c|c|c|c|}
\hline & \multicolumn{8}{|c|}{ Age(years) } & \multirow{3}{*}{ Test of sig. } & \multirow{3}{*}{$P$} \\
\hline & \multicolumn{2}{|c|}{$\begin{array}{c}<30 \\
(n=10)\end{array}$} & \multicolumn{2}{|c|}{$\begin{array}{l}30-39 \\
(n=22)\end{array}$} & \multicolumn{2}{|c|}{$\begin{array}{c}40-50 \\
(n=198)\end{array}$} & \multicolumn{2}{|c|}{$\begin{array}{c}>50 \\
(n=177)\end{array}$} & & \\
\hline & $\mathrm{n}$ & $\%$ & $\mathrm{n}$ & $\%$ & $\mathrm{n}$ & $\%$ & $\mathrm{n}$ & $\%$ & & \\
\hline Total FSD & 1 & 10 & 5 & 22.7 & 99 & 50 & 161 & 90.9 & $\chi^{2}=40.533^{*}$ & $p<0.001^{*}$ \\
\hline Low desire & 2 & 20 & 4 & 18.1 & 64 & 32 & 177 & 100 & $\chi^{2}=38.977$ & $p<0.001^{*}$ \\
\hline Arousal disorder & 2 & 20 & 5 & 22.7 & 71 & 35.8 & 171 & 96.6 & $\chi^{2}=25.553^{*}$ & $p<0.001 *$ \\
\hline Lubrication disorder & 2 & 20 & 2 & 13.6 & 60 & 30 & 166 & 93.7 & $\chi 2=34.505^{*}$ & $p<0.001^{*}$ \\
\hline Orgasm disorder & 2 & 20 & 5 & 22.7 & 71 & 35.8 & 161 & 90.9 & $\chi^{2}=25.011^{*}$ & $p<0.001^{*}$ \\
\hline Satisfaction disorder & 1 & 10 & 5 & 22.7 & 83 & 42 & 163 & 92 & $\chi^{2}=25.635^{*}$ & $p<0.001^{*}$ \\
\hline Pain disorder & 6 & 60 & 9 & 40.9 & 110 & 55.5 & 177 & 100 & $\chi^{2}=50.469^{*}$ & $p<0.001^{*}$ \\
\hline
\end{tabular}

Table 7: Sexual dysfunction in relation to diabetes complications.

\begin{tabular}{|c|c|c|c|c|c|c|c|c|c|c|c|c|}
\hline & \multicolumn{4}{|c|}{ Hypertension } & \multicolumn{4}{|c|}{ Coronary artery disease } & \multicolumn{4}{|c|}{ Peripheral neuropathy } \\
\hline & \multicolumn{2}{|c|}{$\begin{array}{c}\text { Yes } \\
(n=112)\end{array}$} & \multicolumn{2}{|c|}{$\begin{array}{c}\text { No } \\
(n=295)\end{array}$} & \multicolumn{2}{|c|}{$\begin{array}{c}\text { Yes } \\
(n=16)\end{array}$} & \multicolumn{2}{|c|}{$\begin{array}{c}\text { No } \\
(n=391)\end{array}$} & \multicolumn{2}{|c|}{$\begin{array}{c}\text { Yes } \\
(n=364)\end{array}$} & \multicolumn{2}{|c|}{$\begin{array}{c}\text { No } \\
(n=43)\end{array}$} \\
\hline & $\mathrm{n}$ & $\%$ & $\mathrm{n}$ & $\%$ & $\mathrm{n}$ & $\%$ & $\mathrm{n}$ & $\%$ & $\mathrm{n}$ & $\%$ & $\mathrm{n}$ & $\%$ \\
\hline Total FSD & 104 & 92.8 & 166 & 56 & 16 & 100.0 & 254 & 64.9 & 245 & 67 & 25 & 58 \\
\hline$\chi^{2}(\mathrm{p})$ & \multicolumn{4}{|c|}{$18.654(<0.001 *)$} & \multicolumn{4}{|c|}{$8.036 *(<0.001 *)$} & \multicolumn{4}{|c|}{$64.681 *(<0.001 *)$} \\
\hline Low desire & 100 & 89.2 & 137 & 46 & 16 & 100.0 & 221 & 56.5 & 213 & 58.5 & 21 & 48.8 \\
\hline$\chi^{2}(\mathrm{p})$ & \multicolumn{4}{|c|}{$28.690 *(<0.001 *)$} & \multicolumn{4}{|c|}{$10.939 *(0.001 *)$} & \multicolumn{4}{|c|}{$10.274 *(0.001 *)$} \\
\hline Arousal disorder & 85 & 75.8 & 143 & 48.4 & 13 & 81 & 215 & 54.9 & 208 & 57 & 20 & 46.5 \\
\hline$\chi^{2}(\mathrm{p})$ & \multicolumn{4}{|c|}{$10.798 *(0.001 *)$} & \multicolumn{4}{|c|}{$54.773 *(<0.001 *)$} & \multicolumn{4}{|c|}{$10.798 *(0.001 *)$} \\
\hline Lubrication disorder & 84 & 75 & 133 & 45 & 12 & 75 & 205 & 52 & 196 & 53.8 & 21 & 48.8 \\
\hline$\chi^{2}(\mathrm{p})$ & \multicolumn{4}{|c|}{$14.405 *(<0.001 *)$} & \multicolumn{4}{|c|}{$18.654\left(<0.001^{*}\right)$} & \multicolumn{4}{|c|}{$28.690 *(<0.001 *)$} \\
\hline Orgasm disorder & 85 & 75.8 & 143 & 48.4 & 13 & 81 & 215 & 54.9 & 208 & 57 & 20 & 46.5 \\
\hline$\chi^{2}(\mathrm{p})$ & \multicolumn{4}{|c|}{$10.274 *(0.001 *)$} & \multicolumn{4}{|c|}{$10.798 *(0.001 *)$} & \multicolumn{4}{|c|}{$26.635^{*}(<0.001 *)$} \\
\hline Satisfaction disorder & 88 & 78.5 & 155 & 52.5 & 13 & 81 & 230 & 58.8 & 222 & 60.9 & 21 & 48.8 \\
\hline$\chi^{2}(\mathrm{p})$ & \multicolumn{4}{|c|}{$10.939 *(0.001 *)$} & \multicolumn{4}{|c|}{$14.405^{*}\left(<0.001^{*}\right)$} & \multicolumn{4}{|c|}{$28.690 *(<0.001 *)$} \\
\hline Pain disorder & 96 & 85.7 & 194 & 65.7 & 16 & 100 & 274 & 70 & 268 & 73.6 & 22 & 51 \\
\hline$\chi^{2}(\mathrm{p})$ & \multicolumn{4}{|c|}{$18.654(<0.001 *)$} & \multicolumn{4}{|c|}{$26.635^{*}(<0.001 *)$} & \multicolumn{4}{|c|}{$15.701 *(<0.001 *)$} \\
\hline
\end{tabular}




\section{DISCUSSION}

The literature raising attention about woman sexual health and dysfunction in diabetes mellitus is limited, and this aspect of female health problems, is frequently disregarded in ordinary medical practice ${ }^{[9]}$. The present study revealed that $66.3 \%$ of women interviewed have SD with no significant distinction between type I(T1DM) and type II(T2DM) diabetic females. Ahmed et al. ${ }^{[10]}$, in a cross sectional study of diabetic Egyptian ladies observed that occurrence of SD was significantly greater in both T1DM and T2DM organizations (44 and 25\%, respectively) than in the control group (9\%).

Their lower figures may additionally be attributed to the reality that they exclude postmenopausal women. SD used to be stated via $88.7 \%$ of Saudi ladies (of all ages) with $\mathrm{T} 2 \mathrm{DM}^{[11]}$ while it rates for $78.7 \%$ in Iranian ladies $^{[12]}$. A Turkish research on 93 diabetic females with T2DM determined that SD was defined in $55.9 \% \%^{[13]}$ and a Nigerian one claim an equal share ${ }^{[14]}$. In a report about Dutch men and ladies with T2DM, 70\% of Dutch females were diagnosed with some degree of sexual dysfunction $^{[15]}$ while in an Italian sample ${ }^{[16]}$, a Jordanian sample ${ }^{[17]}$ and a Tunisian sample ${ }^{[18]}$ the prevalence of female SD used to be $53.4 \%, 59.6 \%$ and $50 \%$ respectively. After an evaluation and a meta-analysis of 25 studies, Rahmanian et al. ${ }^{[21]}$ concluded that the average occurrence of female SD in women with T2DM was $68.6 \%$.Sexual dysfunction that found in females with DM may also be explained by means of various mechanisms. Hyperglycemia may additionally reduce the vaginal hydration that resulted in reduced lubrication and dyspareunia. Also, increased threat of vaginal infections will increase the threat of vaginal soreness and dyspareunia.Vascular affection, microangiopathy and neuropathy can also leads to diminished genital blood flow, leading to impaired genital arousal response. Psychosocial factors such as adjustment to be a patient with DM, the burden of having chronic lifelong non curable disease like DM, and depression may also impair sexual performance ${ }^{[20]}$.

In a descending order, our participants suffered from troubles in pain, satisfaction, desire, arousal, orgasm and lubrication. Similar outcomes were addressed by Ogbera et al. ${ }^{[14]}$. However, the work of Elyasi et al. ${ }^{[12]}$ showed that the most common SD in diabetic females were issues with lubrication then desire then arousal then satisfaction and lastly dyspareunia. Abu Ali et al. ${ }^{[17]}$ found sexual dissatisfaction to be the commonest $\mathrm{SD}$, then the troubles in lubrication and orgasm followed by troubles in desire, arousal and pain.

In Tunisia the order of SD was as follows: Pain then lubrication then orgasm then arousal then satisfaction and coming lastly the desire ${ }^{[18]}$. The meta-analysis of
Rahmanian et al. ${ }^{[19]}$ study concluded that in anascending order the most common SD in diabetic females were problems in orgasm, desire, arousal, pain, lubrication, and satisfaction. Among our female patients 69\% of them were overweight or obese (i.e. have a BMI over $25 \mathrm{~kg} / \mathrm{m} 2$ ). During the previous few decades, the occurrence of overweight problems have been increasing at a fast pace in each Western societies and the developing world $^{[21]}$. Depending on ethnicity, age and gender, 50-90\% of type 2 diabetes (T2DM) patients have overweight, while patients with BMI over $35 \mathrm{~kg} / \mathrm{m} 2$ are almost 20 times more liable to develop T2DM ${ }^{[22]}$. Duman ${ }^{[8]}$ showed that there is a positive correlation between body mass index and female SD. The link between obesity and SD is complicated and multivariate, with at least three distinct pathways likely: direct outcomes from excessive adipose tissue; consequences from pathophysiologic comorbidities; and consequences mediated through psychological factors ${ }^{[23]}$. Most overweight and fatty females consider themselves to be less attractive, less sexually fascinating and incapable of creating a gratifying romantic relationship, in contrast to females with normal body weight ${ }^{[24]}$.

In the present study, occurrence of SD was related to duration, control, BMI, age and presence of diabetic complications. These results are in agreement with Abu Ali et $a l^{\left[{ }^{[8]}\right.}$ and Esposito et al. ${ }^{[16]}$ while AlMogbel et al. ${ }^{[1]]}$ found that patients' age is related to SD but duration of diabetes was unrelated. Other studies did not find a relation between all these determinants or some of them and occurrence of $\mathrm{SD}^{[12,18,25,26]}$. However, it is difficult to compare the findings of different studies because of dissimilarities in design and the difficulties in differentiation between some factors (e.g. aging) that may be a consequence of diabetes or a natural process

\section{CONCLUSION}

Sexual dysfunction in diabetic women is common The most affected aspects of female sexuality were pain, satisfaction, desire, arousal, orgasm and lubrication. The present study found that Occurrence of SD in these women was related to duration, control, BMI, age and presence of diabetic complications.

\section{CONFLICT OF INTEREST}

There are no conflicts of interest.

\section{REFERENCES}

1. Whiting DR, Guariguata L, Weil C, Shaw J. IDF diabetes atlas: global estimates of the prevalence of diabetes for 2011 and 2030. Diabetes Res Clin Pract 2011;94:311e21. 
2. Centers for Disease Control and Prevention. National Diabetes Statistics Report, 2017. Acessed in October 2019. Available at https://www.cdc.gov/diabetes/ $\mathrm{pdfs} / \mathrm{data} /$ statistics/national-diabetes-statisticsreport.pdf.

3. Hegazi R, El-Gamal M, Abdel-Hady N, Hamdy O. Epidemiology of and risk factors for type 2 diabetes in Egypt. Ann Glob Health. 2015 1;81(6):814-20.

4. Pontiroli AE, Cortelazzi D, Morabito A. Female sexual dysfunction and diabetes: a systematic review and meta-analysis. J Sex Med. 2013;10(4):1044-1051.

5. Mazzilli R, Imbrogno N, Elia J, Delfino M, Bitterman O, Napoli A, Mazzilli F. Sexual dysfunction in diabetic women: prevalence and differences in type 1 and type 2 diabetes mellitus. Diabetes Metab Syndr Obes. 2015;8:97.

6. Duman NB. Frequency of sexual dysfunction and its causative factors among diabetic women in Turkey. Pak J Med Sci. 2014 May;30(3):558-63.

7. Rosen C, Brown J, Heiman S, Leiblum C, Meston R, Shabsigh D, Ferguson R, D'Agostino R. The Female Sexual Function Index (FSFI): a multidimensional self-report instrument for the assessment of female sexual function. J Sex Marital Ther. 2000 1;26(2):191-208.

8. Anis TH, Gheit SA, Saied HS, Al_kherbash SA. Arabic translation of Female Sexual Function Index and validation in an Egyptian population. J Sex Med. 2011; 8(12):3370-8.

9. Gupta L, Parkash S, Khandelwal D, kalra B, Kalra S. Diabetes and female sexual dysfunction. US Endocrinology. 2018; 14(1):35-38.

10. Ahmed MR, Shaaban MM, Sedik WF, Mohamed TY.Prevalence and differences between type 1 and type 2 diabetes mellitus regarding female sexual dysfunction: a cross-sectional Egyptian study.J Psychosom Obstet Gynaecol. 2018 ;39(3):176-181.

11. AlMogbel TA, Amin HS, AlSaad SM, AlMigbal TH. Prevalence of sexual dysfunction in saudi women with Type 2 diabetes: Is it affected by age, glycemic control or obesity?. Pak J Med Sci. 2017 May;33(3):732.

12. Elyasi F, Kashi Z, Tasfieh B, Bahar A, Khademloo M. Sexual dysfunction in women with type 2 diabetes mellitus. IJMS. $2015 ; 40(3): 206$.
13. Tuncel E, Durgun O, Peynirci H, Ersoy C. Sexual dysfunction in female patients with type 2 diabetes mellitus: a cross-sectional single-centre study among Turkish patients. Hum Fertil. 2017 3;20(3):192-9.

14. Ogbera AO, Chinenye S, Akinlade A, Eregie A, Awobusuyi J. Frequency and correlates of sexual dysfunction in women with diabetes mellitus. J Sex Med. 2009 Dec 1;6(12):3401-6.

15. Rutte A, van Splunter MM, van der Heijden AA, Welschen LM, Elders PJ, Dekker JM, Snoek FJ, Enzlin P, Nijpels G.Prevalence and correlates of sexual dysfunction in men and women with type 2 diabetes.J Sex Marital Ther. 2015;41(6):680-90.

16. Esposito K, Maiorino MI, Bellastella G, Giugliano F, Romano M, Giugliano D. Determinants of female sexual dysfunction in type 2 diabetes. Int $\mathbf{J}$ Impot Res. 2010 May;22(3):179.

17. Abu Ali RM, Al Hajeri RM, Khader YS, Shegem NS, Ajlouni KM. Sexual dysfunction in Jordanian diabetic women.Diabetes Care. 2008; 31: 1580-1581.

18. Ammar M, Trabelsi L, Chaabene A, Charfi N, Abid M. Evaluation of sexual dysfunction in women with type 2 diabetes. Sexologies.2017;26(3):17-20.

19. Rahmanian E, Salari N, Mohammadi M, Jalali R.Evaluation of sexual dysfunction and female sexual dysfunction indicators in women with type 2 diabetes: a systematic review and meta-analysis. Diabetol Metab Syndr. 2019 27;11:73.

20. Rockliffe-Fidler C, and Kiemle G. Sexual function in diabetic women: A psychological perspective. Sex Relatsh Ther. 2003; 18:143-159.

21. James WP. Obesity-a modern pandemic: the burden of disease. Endocrinol Nutr. 2013;60 Suppl 1:3-6.

22. Krug EG. Trends in diabetes: sounding the alarm. Lancet. 2016;387(10027):1485-6.

23. Rowland DL, McNabney SM, Mann AR. Sexual function, obesity, and weight loss in men and women. Sex Med Rev 2017; 5:323-338.

24. Adolfsson B, Elofsson S, Rössner S, Unden AL. Are sexual dissatisfaction and sexual abuse associated with obesity? A population-based study. Obes Res. 2012; 12(10): 1702-1709.

25. Enzlin P, Rosen R, Wiegel M, Brown J, Wessells 
H, Gatcomb P, Rutledge B, Chan KL, Cleary PA. Sexual dysfunction in women with type 1 diabetes. Diabetes Care. 2009 May 1;32(5):780-5.
26. Olarinoye J, Olarinoye A. Determinants of sexual function among women with type 2 diabetes in a Nigerian population. J Sex Med. 2008 1;5(4):878-86. 